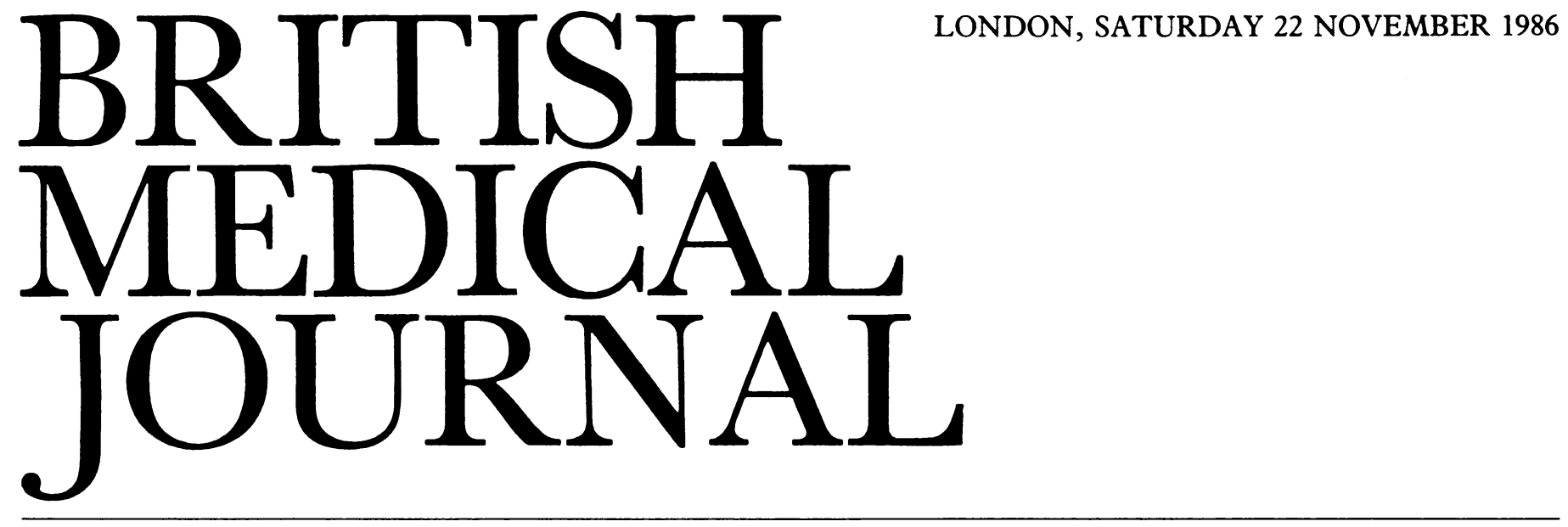

\title{
Syrup of ipecacuanha: is it really useful?
}

Syrup of ipecacuanha is used in managing patients, particularly children, who have taken potential poisons. It is used both as a first aid measure in the home ${ }^{12}$ and as immediate treatment in accident and emergency departments. Such is the belief in its value that health education campaigns have been organised, notably in the United States, to ensure that ipecacuanha is available in the home ${ }^{3}$ and that parents know how to use it safely. ${ }^{4}$ But is ipecacuanha so valuable?

Despite changes in prescribing habits in the past decade toxic agents remain readily available to children and adults alike. Although attempts should still therefore be made to reduce the risk of systemic toxicity by reducing absorption, important morbidity from acute poisoning in children is uncommon. British studies have shown that fewer than $4 \%$ of children admitted to hospital after the alleged ingestion of household products developed severe symptoms. ${ }^{5}$ Similarly, only $12 \%$ of patients admitted to paediatric units in Britain after taking toxic agents suffered serious complications ${ }^{6}$ and only $4.5 \%$ of those admitted in West Germany. ${ }^{7}$ Furthermore, the mortality from accidental poisoning in children in a large Australian study was less than $0 \cdot 1 \%{ }^{8}$

The low morbidity and mortality from acute poisoning, even in children admitted to hospital, suggest that many incidents are scares rather than true poisonings; the use of syrup of ipecacuanha in almost every case of suspected poisoning is therefore inappropriate.

Ipecacuanha is derived from the dried root of Cephaelis ipecacuanha and Cephaelis acuminata, and its active alkaloids are emetine and cephaeline. Cephaeline is twice as potent an emetic as emetine, and both alkaloids induce vomiting by a central action. In addition, emetine has a direct irritant action on the gastric mucosa, which usually causes vomiting within 30 minutes of a patient being given ipecacuanha; later vomiting results from the central action of both alkaloids. Syrup of ipecacuanha effectively induces emesis in children of any age ${ }^{29-15}$ and in adults. ${ }^{16}$ Provided that the dose is appropriate to the age of the patient, and liberal oral fluids are administered, almost all patients vomit.

But does ipecacuanha prevent absorption of toxins? Corby et $a l^{17}$ gave children $1 \mathrm{~g}$ of magnesium hydroxide as a marker in $200 \mathrm{ml}$ of fluid immediately before giving $20-40 \mathrm{ml}$ of syrup of ipecacuanha. The mean recovery of marker was only 28 (SEM 7)\%. In a further study in children with salicylate poisoning the mean recovery of aspirin after ipecacuanha was 143 (SD 78) mg. ${ }^{18}$ More recently, Neuvonen et al gave adult volunteers $20 \mathrm{ml}$ of syrup of ipecacuanha with $300 \mathrm{ml}$ water 30 minutes after therapeutic doses of paracetamol, aminophylline, and tetracycline. ${ }^{19}$ Although every volunteer vomited, there was no significant effect on the absorption of paracetamol and aminophylline, though absorption of tetracycline was reduced. In contrast, activated charcoal had a significantly greater effect when given 30 minutes after dosing. Curtis et al simulated overdose conditions more realistically by giving adult volunteers $1944 \mathrm{mg}$ of aspirin in 24 tablets. ${ }^{20}$ Ten subjects were given ipecacuanha one hour later, and the mean recovery of salicylate in the urine was reduced from 96.3 (SD 7.5)\% in controls to $70.3(11.8) \%$ $(\mathrm{p}<0.01)$. Again, however, activated charcoal was more effective than ipecacuanha $(\mathrm{p}<0.05)$. Recently, Kulig et al found that syrup of ipecacuanha did not alter the clinical course of poisoned patients who were alert on presentation to hospital. ${ }^{21}$

An important objection to ipecacuanha is that its effects may mimic those of poisoning and thus introduce uncertainty as to their cause. For example, if the dose of ipecacuanha is large enough vomiting may be persistent. ${ }^{19} 22$ Very rarely, vomiting induced by ipecacuanha has led to serious complications ${ }^{23}{ }^{24}$ and even death ${ }^{25}$; in addition, diarrhoea, lethargy, and drowsiness occur in up to $13 \%$ of cases. ${ }^{22}{ }^{26}$ Finally, giving ipecacuanha may prevent the use of specific treatment such as oral methionine and activated charcoal.

In summary, syrup of ipecacuanha is an efficient and rapidly acting emetic that only rarely produces serious sequelae. Although its use may satisfy the innate desire of parents, doctors, and nursing staff to "do something," there is no evidence that it prevents drug absorption or systemic toxicity. The use of syrup of ipecacuanha in managing poisoning should therefore be reconsidered.

West Midlands Poisons Unit,

J A VALE Director

Dudley Road Hospital

Birmingham B18 7QH

Guy's Hospital,

London SE1 9RT

T J MEREDITH Senior registrar in medicine

A T PROUdFOOT Director

Regional Poisoning Treatment Centre,

Royal Infirmary,

Edinburgh EH3 9YW

Correspondence to: Dr Vale. 
1 Mowry JB, Sketris IS, Czajka PA. Ipecac syrup for poisonings at home: availability, compliance, and response monitored by telephone. Am $\mathcal{F}$ Hosp Pharm 1981;38: 1028-30.

2 Veltri JC, Temple AR. Telephone management of poisonings using syrup of ipecac. Clinical Toxicology 1976;9:407-17

3 Wester TB. Project Ipecac: an accident prevention program of the Robeson County Department of Health. NC Med f 1985;46:425-6.

4 Dershewitz RA, Posner MK, Paichel W. The effectiveness of health education on home use of ipecac. Clin Pediatr (Phila) 1983;22:268-70.

5 Craft AW, Sibert JR. Morbidity of accidental poisoning from household products. In: Report of the child resistant closure working party. London: Daniel J Edelman, 1983:20-4. (Chairman W G Scobie.

6 Lawson GR, Craft AW, Jackson RH. Changing pattern of poisoning in children in Newcastle, 1974-81. Br Med f 1983;287:15-7.

7 Christen H-J, Zink C, Zink A, Korporal J. Accidental poisoning in children from the epidemiological viewpoint. Vet Hum Toxicol 1981;23:321-7.

Pearn J, Nixon J, Ansford A, Corcoran A. Accidental poisoning in childhood: five year urban population study with 15 year analysis of fatality. Br.Med f 1984;288:44-6.

9 Robertson WO. Surup of ipecac-a slow or fast emetic? Am 7 Dis Child 1962;103:136-9.

$10 \mathrm{Karlsson} B$, Noren L. Ipecacuanha and copper sulphate as emetics in intoxication in children. Acta Paediatr Scand 1965;54:331-5.

11 Reid DHS. Ipecac syrup for poisoned children. Lancet 1969;i:261

2 MacLean WC. A comparison of ipecac syrup and apomorphine in the immediate treatment of ingestion of poisons. F Pediatr 1973;82:121-4.

3 Dean BS, Krenzelok EP. Syrup of ipecac . . $15 \mathrm{ml}$ versus $30 \mathrm{ml}$ in pediatric poisonings. Clinical Toxicology 1985;23:165-70.

14 Litovitz TL. Klein-Schwartz W, Oderda GM, Matyunas NJ, Wiley S, Gorman RL. Ipecac administration in children younger than 1 year of age. Pediatrics 1985;76:761-4.

5 Krenzelok EP, Dean BS. Syrup of ipecac in children less than one year of age. Clinical Toxicology 1985;23:171-6.

6 Ilett KF, Gibb SM, Unsworth RW. Syrup of ipecacuanha as an emetic in adults. Med $\mathcal{J}$ Aust 1977;2:91-3.

17 Corby DG, Decker WJ, Moran MJ, Payne CE. Clinical comparison of pharmacologic emetics in children. Pediatrics 1968;4:361-4.

18 Boxer L, Anderson FP, Rowe DS. Comparison of ipecac-induced emesis with gastric lavage in the treatment of acute salicylate ingestion. $\mathcal{J}$ Pediatr $1969 ; 74: 800-3$.

19 Neuvonen PJ, Vartiainen M, Tokola O. Comparison of activated charcoal and ipecac syrup in prevention of drug absorption. Eur f Clin Pharmacol 1983;24:557-62.

20 Curtis RA, Barone J, Giacona N. Efficacy of ipecac and activated charcoal/cathartic: prevention of salicylate absorption in a simulated overdose. Arch Intern Med 1984;144:48-52.

21 Kulig K, Bar-Or D, Cantrill SV, Rosen P, Rumack BH. Management of acutely poisoned patients without gastric emptying. Ann Emerg Med 1985;14:562-7.

22 Czajka PA, Russell SL. Nonemetic effects of ipecac syrup. Pediatrics 1985;75:1101-4.

23 Timberlake GA. Ipecac as a cause of Mallory-Weiss syndrome. South Med $\mathcal{f}$ 1984;77:804-5.

24 Tandberg D, Liechty EJ, Fishbein D. Mallory-Weiss Syndrome: an unusual complication of ipecac induced emesis. Ann Emerg Med 1981;10:521-3.

25 Robertson WO. Syrup of ipecac associated fatality: a case report. Vet $H$ um Toxicol 1979;21:87-9.

26 Chafee-Bahaman C, Lacouture PG, Lovejoy FH. Risk assessment of ipecac in the home. Pediatrics 1985;75:1105-9.

\section{The health of travellers}

A recent report from Kent suggests that travellers (nomadic people who are not necessarily of Romany origin) have serious health problems. ${ }^{1}$ In particular, their perinatal mortality rate is a fifth higher than the average national rate and their infant mortality rate $40 \%$ higher. The conditions in which they live are often very poor, and the question arises whether health authorities should take some specific action.

Counting travellers is difficult, but the Department of the Environment found 9600 traveller caravans with an estimated total population of between 30000 and 50000 in July $1984 .^{2}$ Travellers are concentrated in Kent and East Anglia, where temporary seasonal agricultural employment is most available.

Evidence on the health of travellers was thin until the recent study from the University of Kent's Health Services Research Unit, ${ }^{1}$ although a study by the Save the Children Fund in 1983 described a large population of travellers in East Anglia as "disadvantaged in health and health care." 3 In the Kent study health visitors questioned mothers with children aged under 15 on all traveller sites in Kent, and the degree of cooperation was high. Many families lacked running water, lavatories, and electricity. A third of families did not have access to a lavatory on site, whereas in the 1981 national census $4 \%$ of all British households lacked or shared an inside lavatory. In $19827 \%$ of social class $\mathrm{V}$ households lacked a bath and shower, but $14 \%$ of traveller families in the study not only did not have a bath or shower but also lacked access to running water on site. Conditions on private caravan sites were least primitive, and those on illegal sites were the worst. Conditions on some local authority sites were as bad as on illegal sites.

The most important health findings of the study relate to $\widehat{\Omega}$ mother and child health. The average number of children was $3 \cdot 1$ in each family compared with the national average of $\mathbb{D}_{\mathbb{D}}$ under two. Some $16 \%$ of mothers interviewed had had five or क more children compared with less than $2 \%$ in the population $\varrho$ as a whole. ${ }^{4}$ The women did, however, have access to reliable contraceptive methods. As well as perinatal and infant mortality rates being higher than the national average, the prevalence of low birthweight babies (less than $2500 \mathrm{~g}$ ) was about double the national rate. ${ }^{5}$ Prolonged breast feeding was uncommon. Child surveillance was substandard, and rates of child immunisation were only about a third of the national average. Sadly the study did not include a settled control group matched for social class. The effects of social class thus cannot be disentangled from the effects of a "nomadic habit of life."

What should be done in response to these findings? There is clearly a need for local authorities to provide more and better appointed sites for traveller families and for district $\delta$ health authorities to take action to improve standards of child $\infty$ surveillance and childhood immunisation. The poor reproductive performance of traveller women also needs attention, but as we do not understand the reasons for this poor $\frac{9}{5}$ performance health authorities can do little except perhaps $N$ promote research. To improve standards of child surveillance and immunisation rates traveller families in each district should first be identified. Services might then be taken to sites. Travellers may not use traditional clinic or general practitioner based services. Responsibility for improving the health care of traveller families must be allocated to a named individual - a health visitor might be the best person. Some health authorities have already done this.

\section{P C WALKER}

District General Manager,

Frenchay Health Authority, Bristol BS16 1ND

1 Pahl J, Vaile M. Health and health care among travellers. Canterbury: University of Kent, 1986 (Health Services Research Unit.)

2 Department of the Environment. Count of gypsy caravans, regional totals. London: HMSO, 1984. 3 Save the Children Fund. The health of traveller mothers and children in East Anglia. London: Save the Children Fund, 1983.

4 Office of Population Censuses and Surveys. Fertility trends in England and Wales during 1984. London: HMSO, 1985.

5 Office of Population Censuses and Surveys. Infant and perinatal mortality 1980. London: HMSO, 1982.

\section{Urinary incontinence after stroke}

Urinary incontinence after stroke is common, uncomfortable, and undignified and often constrains rehabilitation and discharge. It carries a bad prognosis for rehabilitation ${ }^{12}$ and may be of more specific prognostic importance than a history of depression of consciousness. ${ }^{3}$ Although detrusor instability, with consequent urge incontinence, is associated with certain cerebral lesions, ${ }^{4}$ other more peripheral or, indeed, external factors may be important. A mobile alert patient fumbling left handed with his fly buttons after 60 years of dexterity and continence may wet himself. A more dependent patient who needs help to urinate into a bedpan or bottle

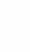

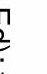

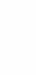
(1) 